\title{
Retardo mental: periculosidade e responsabilidade penal
}

\author{
Mental retardation: dangerousness and penal responsibility
}

Alexandre Martins Valençâa, , Mauro Vitor Mendlowicz' Isabella Nascimento33, Talvane Marins de Moraes³, Antonio Egidio Nardi ${ }^{3}$

\section{RESUMO}

O objetivo do presente artigo é discutir os conceitos de periculosidade e responsabilidade penal, por meio do relato de caso de uma paciente com diagnóstico de retardo mental que cometeu homicídio. Ela foi submetida à medida de segurança detentiva em hospital psiquiá-

\section{Palavras-chave}

Violência, internação compulsória de doente mental, psiquiatria forense, comportamento.

\section{Keywords}

Violence, commitment of mentally ill, forensic psychiatry, behaviour. trico de custódia e segurança, na cidade do Rio de Janeiro, Brasil. Este relato demonstra a importância da psicopatologia e da psiquiatria na prática forense, auxiliando o magistrado na determinação da responsabilidade penal do indivíduo portador de transtorno mental ou retardo mental. O estudo do comportamento violento em indivíduos com transtornos psiquiátricos pode contribuir para o seu entendimento, prevenção e tratamento.

\begin{abstract}
The objective of this article was to discuss the concepts of dangerousness and penal responsibility, through the presentation and analysis of the case of a patient with a diagnosis of mental retardation who committed murder. She was found not guilty by reason of insanity and was criminally committed to a forensic hospital in the city of Rio de Janeiro, Brazil. This case shows the importance of psychopathology and forensic psychiatry, which may help the judge to rule about the penal responsibility of an individual with a psychiatric disorder or mental retardation. The investigation of violent behavior of individuals with psychiatric disorders may contribute to increase the understanding and foster the prevention and early treatment of this kind of behaviour.
\end{abstract}

\section{INTRODUÇÃO}

No Direito Penal, periculosidade é a probabilidade de o agente vir ou tornar a praticar ato previsto como crime. Pode ser presumida pela lei e, assim, resultar na aplicação compulsória de medida de segurança ou ser reconhecida pelo juiz. A medida de segurança fica reservada ao agente inimputável, podendo ser de dois tipos: a detentiva, que determina a internação em hospital de custódia e tratamento psiquiátrico, e a restritiva, na qual o tratamento psiquiátrico é em regime ambulatorial. Seu prazo de duração varia de um a três anos, sendo esse tempo determinado por autoridade judicial e dependente da natureza (gravidade) do ato praticado. A medida de segurança só pode ser interrompida após o término desse prazo e com a constatação de cessação de periculosidade, por meio do laudo pericial.

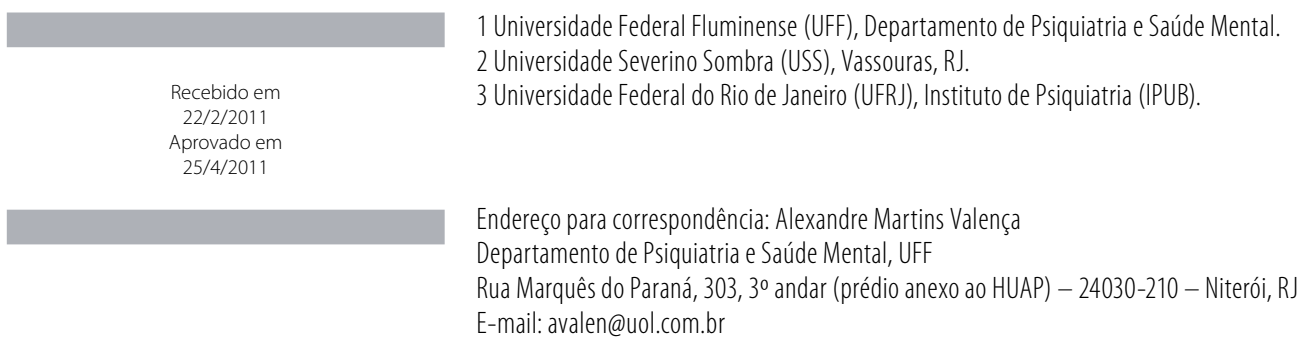


Dois conceitos importantes são o de responsabilidade e imputabilidade, significando esta a condição psíquica da punibilidade, enquanto aquela designaria a obrigação de responder penalmente ou de sofrer a pena por um fato determinado, pressuposta a imputabilidade. De acordo com Vargas², o conceito básico de imputabilidade seria a condição de quem tem aptidão para realizar com pleno discernimento um ato. Representa a imputabilidade uma relação de causalidade psíquica entre o fato e o seu autor. A responsabilidade é definida como a existência dos pressupostos psíquicos pelos quais alguém é chamado a responder penalmente pelo crime que praticou.

No Brasil, o critério adotado pelo nosso Código Penal ${ }^{3}$ para avaliação da responsabilidade penal é o biopsicológico: a responsabilidade só é excluída se o agente, em razão de doença mental ou retardamento mental, era, no momento da ação, incapaz de entendimento ético-jurídico e/ou de autodeterminação. Para a aplicação desse critério, o perito deve analisar os seguintes itens $s^{4,5}$ : verificação da existência ou não de doença mental ou retardo mental pelo exame de sanidade mental; avaliação do nexo de causalidade entre estes e o crime; avaliação da capacidade de entendimento e de autogoverno (deliberação).

De acordo com a Associação Americana de Retardo Mental (AAMR) (apud Dwyer e Frierson ${ }^{6}$ ), a prevalência de retardo mental na população geral é de 1,5\% a 2,5\%, porém no sistema de justiça criminal ela é de $4 \%$ a $10 \%$. Adicionalmente, a AAMR relatou que pessoas com retardo mental são mais vulneráveis ao sistema de justiça criminal devido à sua falta de cautela ao falar, capacidade crítica limitada em relação às consequências de seu comportamento e influencibilidade em relação aos outros.

Estudos também têm revelado anormalidades neurológicas em pessoas acusadas ou presas por homicídio. Essas anormalidades têm sido descobertas por exame neurológico e estudos de EEG e de neuroimagem. Blake et al.' estudaram 31 indivíduos que aguardavam sentença por acusação de homicídio. Eles foram submetidos a exames neurológicos diversos, incluindo EEG, avaliação neuropsicológica e estudos de neuroimagem. Nessa amostra foram encontrados 5 casos de síndrome alcoólica fetal, 5 casos de retardo mental com QI menor que 70 e 4 casos com inteligência limítrofe (QI entre 71 e 80). Um histórico de abuso de álcool persistente foi encontrado em 17 indivíduos (55\%). Nove indivíduos apresentavam alterações cerebrais, especialmente atrofia ou lesão da substância branca.

Hafner e Boker (1982) (apud Martell') acompanharam 533 indivíduos que entraram no sistema de saúde mental forense da Alemanha ao longo de um período de 10 anos. Seus dados sugeriram que $33,6 \%$ desses pacientes apresentavam um diagnóstico que refletia dano cerebral orgânico, incluindo retardo mental $(12,7 \%)$, lesão cerebral adquirida na vida adulta (8\%), atrofia cerebral $(7,5 \%)$ e epilepsia $(5,4 \%)$.
Apresentaremos agora o caso de uma mulher que assassinou a avó materna. Durante o estabelecimento do processo criminal, houve determinação judicial no sentido da realização de avaliação psiquiátrico-forense (incidente de insanidade mental), sendo a paciente considerada inimputável em virtude de desenvolvimento mental retardado. Ela cumpre medida de segurança, na forma de internação em hospital de custódia e segurança (manicômio judiciário), na cidade do Rio de Janeiro.

Este estudo é parte do projeto de pesquisa "Comportamento Violento em Indivíduos com Transtornos Mentais", aprovado pelo Comitê de Ética em Psiquiatria do Instituto de Psiquiatria (IPUB) da Universidade Federal do Rio de Janeiro (UFRJ). A paciente em questão aceitou voluntariamente a participação na pesquisa. Ela não é interditada, gozando de direitos civis. Na ocasião da entrevista, foram explicados todos os objetivos da pesquisa, com linguagem simples e apropriada para a paciente, e ela denotou compreender aquilo que the fora explanado ao concordar em participar da pesquisa.

\section{CASO CLÍNICO}

J, 24 anos, natural do Rio de Janeiro, cor parda, solteira, sem profissão, grau de instrução analfabeta, residindo com familiares.

Diversas informações foram colhidas por meio do laudo psiquiátrico pericial e descrições do caso, no prontuário hospitalar da paciente. Consta nos autos do processo criminal que, no ano de 2006, a paciente desferiu vários golpes de arma branca contra a sua avó materna, pelo fato de esta última se negar a dar dinheiro para a paciente comprar um guaraná. A vítima faleceu. Havia relato de várias agressões físicas anteriores à vítima, perpetradas pela paciente em questão, assim como passado de duas internações psiquiátricas, motivadas por episódios de agitação e heteroagressividade. Em seus antecedentes pessoais, havia histórico de atraso no desenvolvimento da linguagem (começou a falar aos 4 anos de idade) e do desenvolvimento psicomotor (andou aos 2 anos, controle esfincteriano vesical e anal aos 5 anos de idade). Também já tinha sido acompanhada na APAE (Associação de Pais e Amigos dos Excepcionais). Só aprendeu a escrever o próprio nome, com muita dificuldade, nunca tendo aprendido a ler. A paciente nunca desenvolveu nenhuma atividade profissional e nunca aprendeu a cozinhar alimentos; por vezes ela varria a casa, atividade que gostava de fazer. Nunca teve namorados, relacionando-se apenas com familiares e alguns vizinhos próximos.

No exame psiquiátrico pericial (Laudo de Exame de Sanidade Mental), foram descritas pobreza ideativa e baixa capacidade de abstração e raciocínio, não havendo atividade delirante ou alucinatória. Também foram descritas irritabili- 
dade e inquietação motora. A paciente foi considerada inimputável, em virtude de desenvolvimento mental retardado (grau moderado), e cumpre medida de segurança na forma de internação no Hospital de Custódia e Tratamento Psiquiátrico há dois anos e meio.

No exame psiquiátrico relacionado ao estudo do caso (realizado após a admissão da paciente no hospital), estavam presentes sinais e sintomas de desenvolvimento mental retardado, como escasso cabedal mental (conjunto de conhecimentos que o indivíduo tem acerca do mundo que o cerca), pobreza ideativa e concretude e perseveração do pensamento. A paciente apresentou, durante o exame, grande dificuldade de expressão verbal. Admitiu o delito (assassinato da avó), sem nenhuma crítica, afirmando: "eu gosto de guaraná e ela não quis me dar dinheiro para eu comprar guaraná". Também foi registrada nesse exame grande dificuldade de realização de cálculos simples e interpretação de provérbios populares, denotando dificuldade em expressar o significado de palavras comuns do nosso vocábulo. Não estavam presentes sintomas psicóticos (delírios e alucinações). Expressão afetiva infantilizada (puerilidade). O diagnóstico psiquiátrico foi realizado com base na clínica apresentada, por meio da análise dos antecedentes pessoais, anamnese e exame psicopatológico da paciente. Foram utilizados os critérios da Classificação Internacional de Doenças (CID-10²), sendo, dessa forma, formulada a hipótese diagnóstica de Retardo Mental Moderado (F 71).

\section{DISCUSSÃO}

Quando J foi submetida à perícia psiquiátrico-forense para avaliação da responsabilidade penal, foi constatado que ela apresentava elevada periculosidade, substanciada pelos seguintes aspectos: comportamento agressivo prévio ao delito; comportamento violento e agressivo dirigido contra membro de sua família; presença de retardo mental moderado; delito praticado por falta de controle sobre os impulsos agressivos; falta de insight, não conseguindo realizar crítica satisfatória ao comportamento relacionado ao delito de homicídio. Como a periculosidade dela foi considerada significativa, foi recomendada a sua internação em manicômio judiciário.

De acordo com Palomba ${ }^{10}$, os deficientes mentais podem apresentar apenas deficiências de inteligência, sem desvios de conduta, mas outros podem apresentar acentuadamente desvio de conduta, por excitabilidade afetiva e volitiva, indiferentismo e instabilidade emocional. O egoísmo e a falta de crítica completariam o quadro clínico desses indivíduos. No caso da paciente, esta relatou que desferiu golpe de arma branca contra a avó por esta ter se negado a dar-Ihe dinheiro para a compra de um refrigerante, havendo impulsividade e total desproporcionalidade entre motivo e reação por parte de J.
Para West (1982) apud Faulk"1', baixo Ql é um fator importante para o desenvolvimento de comportamento delituoso, e indivíduos com retardo mental cometem mais delitos do que a população geral, com QI normal. Ainda de acordo com esse autor, haveria uma associação estatística com outros fatores como baixo nível socioeconômico, como no caso em questão. O retardo mental também pode ser um fator criminogênico, porque o indivíduo é menos capaz, intelectualmente, de lidar com situações de estresse e, dessa forma, ficar facilmente frustrado ou irritado, reagindo de forma inadequada quando contrariado.

No caso da paciente, todas as suas reações emocionais e ações agressivas foram dirigidas contra a sua avó materna, com quem convivia em ambiente doméstico. Alguns estudos têm mostrado que a mulher tende a permanecer mais tempo em ambiente doméstico, em contato com familiares $^{12}$, daí o comportamento violento ser mais frequentemente dirigido a esses membros, o que é ilustrado pelo presente caso. É importante que os clínicos considerem o potencial de violência praticada por mulheres igualmente sério e importante como o do homem.

Em um estudo com 693 homicidas finlandeses, Eronen et al. ${ }^{13}$ encontraram que o retardo mental não aumentou o risco de homicídio em homens, porém resultou em um pequeno aumento deste risco para mulheres, embora não de forma estatisticamente significativa. O caso apresentado ilustra esse aspecto levantado por esses autores. Uma história passada de violência tem sido consistentemente considerada como preditiva de violência subsequente, em diversas populações de pacientes ${ }^{14}$. No caso apresentado, a paciente tinha histórico prévio de conduta agressiva, inclusive dirigida contra a própria avó materna, antes da perpetração do homicídio dela.

No que diz respeito à avaliação pericial, dentro do critério biopsicológico ${ }^{2,15}$, a paciente apresentava desenvolvimento mental retardado em grau moderado (componente biológico), o que acarretou a ela incapacidade de entendimento (deficiência de inteligência) e determinação (debilidade da vontade). Houve nexo de causalidade entre o desenvolvimento mental retardado e o delito. A perícia psiquiátrico-forense concluiu, neste caso, que, em virtude de desenvolvimento mental retardado, a paciente era, na época dos fatos, inteiramente incapaz de entender o caráter ilícito dos fatos ou de determinar-se de acordo com esse entendimento ( $c a-$ put do art. 26 do Código Penal). Em outras palavras, a paciente foi incapaz de ter crítica em relação à antijuridicidade de seus atos, deixando-se levar facilmente por impulsos hostis em relação à sua avó (vítima), agredindo-a de forma despropositada e impulsiva.

Sem dúvida, casos como esse, de homicídio intrafamiliar, são às vezes acompanhados de dificuldades para a equipe técnica de atendimento, que deve estar atenta às suas reações de contratransferência. É fundamental que o paciente 
se sinta bem aceito por parte de toda a equipe que manejará o seu tratamento.

Um aspecto relevante nesses casos é observar o meio social que receberá o paciente após sua possível desinternação: qual a situação da família, qual o interesse desta em recebê-lo, qual a ligação afetiva do paciente com a família. Esta deve estar ciente que a finalidade da internação e do tratamento é prevenir novos episódios de distúrbios comportamentais. É importante que a equipe avalie e atue terapeuticamente em situações de rejeição do paciente por parte da família. Frequentemente, essa família denotará dificuldades em aceitá-lo de volta em sua residência. Desde o início da internação, a equipe deverá tentar promover a reaproximação do paciente com a família, por meio de visitas frequentes ao manicômio e promoção da boa relação entre paciente e família. As saídas terapêuticas antes da desinternação, obtidas com autorização judicial, podem ser facilitadoras desse convívio.

\section{CONCLUSÃO}

Esse caso demonstra a importância da psicopatologia e da psiquiatria forense, que auxiliam o juiz na determinação da responsabilidade penal do indivíduo portador de transtorno mental ou retardo mental. O laudo psiquiátrico bem fundamentado é essencial, nesse aspecto.

São necessários estudos que explorem o risco de violência em mulheres com transtorno mental ou retardo mental de diversas populações, dessa forma avaliando os benefícios de intervenções terapêuticas nesses fatores, na redução do risco de comportamento violento.

\section{REFERÊNCIAS}

1. Mecler K. Doença mental e periculosidade: evolução do conceito. Arq Bras Psiquiatr Neurol Med Legal. 2000;72:5-9.

2. Vargas HS. Manual de psiquiatria forense. Rio de Janeiro: Livraria Freitas Bastos; 1990.

3. Código de Processo Penal. 3a ed. São Paulo: Revista dos Tribunais; 1998.

4. Taborda JGV. Criminal justice system in Brazil: functions of a forensic psychiatrist. Int J Law Psychiatry. 2001;24:371-86.

5. Taborda JGV, Chalub M, Abdala FE. Psiquiatria forense. Porto Alegre: Artmed; 2004.

6. Dwyer GR, Frierson RL. The presence of low $1 Q$ and mental retardation among murder defendants referred for pretrial evaluation. J Forensic Sci. 2006;251:678-82.

7. Blake P, Pincus J, Buckner C. Neurologic abnormalities in murderers. Neurology. 1995:45:1641-7.

8. Martell DA. Estimating the prevalence of organic brain dysfunction in maximum-security forensic psychiatric patients. J Forensic Sci. 1992;37(3):878-93.

9. Classificação de Transtornos Mentais e de Comportamento da CID-10. Porto Alegre: Artes Médicas; 1992

10. Palomba GA. Tratado de psiquiatria forense. São Paulo: Atheneu; 2003.

11. Faulk M. Basic forensic psychiatry. 2nd ed. London: Blackwell Scientific Publications; 1994.

12. Robbins PC, Monahan J, Silver E. Mental disorder, violence and gender. Law Hum Behav. 2003;27:561-71.

13. Eronen M, Hakola P, Tiihonen J. Mental disorders and homicidal behavior in Finland. Arch Gen Psychiatry. 1996;53:497-501.

14. Steinert T. Prediction of inpatient violence. Acta Psychiatr Scand. 2002;106(Suppl 412):133-41

15. Valença AM, Nardi AE. Responsabilidade penal no transtorno bipolar. J Bras Psiquiatr. 2010;59(1):77-9. 